\title{
Discussion/Reply
}

\section{Discussion of the Paper "A New Method Based on the F-Curve for Characterizing Fluid Flow in Continuous Casting Tundishes" by Li et al.}

\author{
BERNARDO MARTINS BRAGA \\ and ROBERTO PARREIRAS TAVARES
}

https://doi.org/10.1007/s11663-018-1377-6

(c) The Minerals, Metals \& Materials Society and ASM International 2018

Li et al. ${ }^{[1]}$ identified a failure of the "Combined Model" proposed by Sahai and Emi. ${ }^{[2]}$ Specifically, the "Combined Model" predicts a large dead volume fraction for a well-mixed tank $\left(V_{\mathrm{d}} / V \cong 0.406\right)$, while it is in fact null for this ideal flow. In order to overcome this problem, the authors proposed a "New Method" for evaluating the dead volume fraction based on the $F$-curve-Eq. [5] of the original paper.

Unfortunately, the "New Method" also suffers from a similar problem. For the ideal plug flow, ${ }^{[3]}$ the actual dead volume fraction is null. However, the "New Method" would predict a negative dead volume fraction for this case. Since no fluid stays more than two residence times in a plug flow vessel $\left(V_{2} / V=0\right)$, the dead volume fraction predicted is $V_{\mathrm{d}} / V=V_{2} / V-$ $\exp (-2) \cong-0.135$. Therefore, neither the "Combined Model" nor the "New Method" has sound theoretical basis. These models should be regarded as tentative index for comparing tundish performance.

Nonetheless, there are other methods available in the literature for characterizing fluid flow in tundishes that may be used.

In general, one may fit the parameters of a suitable tundish model to the experimental RTD by means of the regression technique as it was performed by some authors. ${ }^{[4,5]}$ As an example, suppose that each tundish strand can be modeled by a compartment model similar

BERNARDO MARTINS BRAGA and ROBERTO PARREIRAS TAVARES are with the Department of Metallurgical and Materials Engineering, Engineering School, Federal University of Minas Gerais, Ave. Presidente Antônio Carlos, No. 6627, Belo Horizonte, Minas Gerais 31270-901, Brazil. Contact e-mail: bernardombraga@hotmail.com Manuscript submitted April 2, 2018.

Article published online August 3, 2018. to that considered by $\mathrm{Li}$ et al. ${ }^{[1]}$ : a well-mixed flow volume in series with plug flow volume and a dead volume. The corresponding $F$-curve is ${ }^{[3]}$

$$
F(\theta)=\left\{\begin{array}{c}
0, \quad \theta<V_{\mathrm{p}} / V \\
1-e^{-\left(\theta-V_{\mathrm{p}} / V\right) /\left(V_{\mathrm{m}} / V\right)}, \quad \theta \geq V_{\mathrm{p}} / V
\end{array}\right.
$$

where $\theta$ is the dimensionless time:

$$
\theta=\frac{Q \cdot t}{V},
$$

where $Q$ is the fluid flow rate through the strand $\left(\mathrm{m}^{3} /\right.$ $\mathrm{s}), t$ is the time (s), $V$ is the total tundish volume $\left(\mathrm{m}^{3}\right)$, $V_{\mathrm{p}} / V$ is the plug flow volume fraction, and $V_{\mathrm{m}} / V$ is the well-mixed flow volume fraction. The dead volume fraction $\left(V_{\mathrm{d}} / V\right)$ for this model is

$$
\frac{V_{\mathrm{d}}}{V}=1-\frac{V_{\mathrm{p}}}{V}-\frac{V_{\mathrm{m}}}{V} .
$$

It is noteworthy that a steel volume that is "dead" for a strand may be "active" for another strand.

Model parameters $\left(V_{\mathrm{p}} / V, V_{\mathrm{m}} / V\right.$, and $\left.V_{\mathrm{d}} / V\right)$ can be determined by means of the method of nonlinear least squares, which is commonly used for nonlinear regression. ${ }^{[6]}$ More specifically, the solution of the following minimization problem should be obtained:

$$
\min S=\sum_{j=1}^{N}\left(F_{j}-F_{\exp , j}\right)^{2}
$$

subject to

$$
\begin{gathered}
\frac{V_{\mathrm{p}}}{V} \geq 0, \\
\frac{V_{\mathrm{m}}}{V} \geq 0, \\
\frac{V_{\mathrm{p}}}{V}+\frac{V_{\mathrm{m}}}{V} \leq 1,
\end{gathered}
$$

where $S$ is the least-squares function, $j$ is the data index, $N$ is the total number of data points, $F_{j}$ is the $F$-curve calculated using Eq. [1] at the $j$ th time instant, and $F_{\exp , j}$ is the experimental $F$-curve at the same time instant.

In order to illustrate this approach, it was applied to the RTD data measured by Mendonça ${ }^{[7]}$ in a water physical model of a two-strand symmetrical tundish. Figure 1 shows the results obtained for the bare physical model (i.e., without any flow modifier or gas injection). Compartment model parameters were found using the built-in Solver of Microsoft Excel ${ }^{[8]}$ and they are $V_{\mathrm{p}} /$ $V \cong 0.401, V_{\mathrm{m}} / V \cong 0.599$, and $V_{\mathrm{d}} / V=0$. On the other 


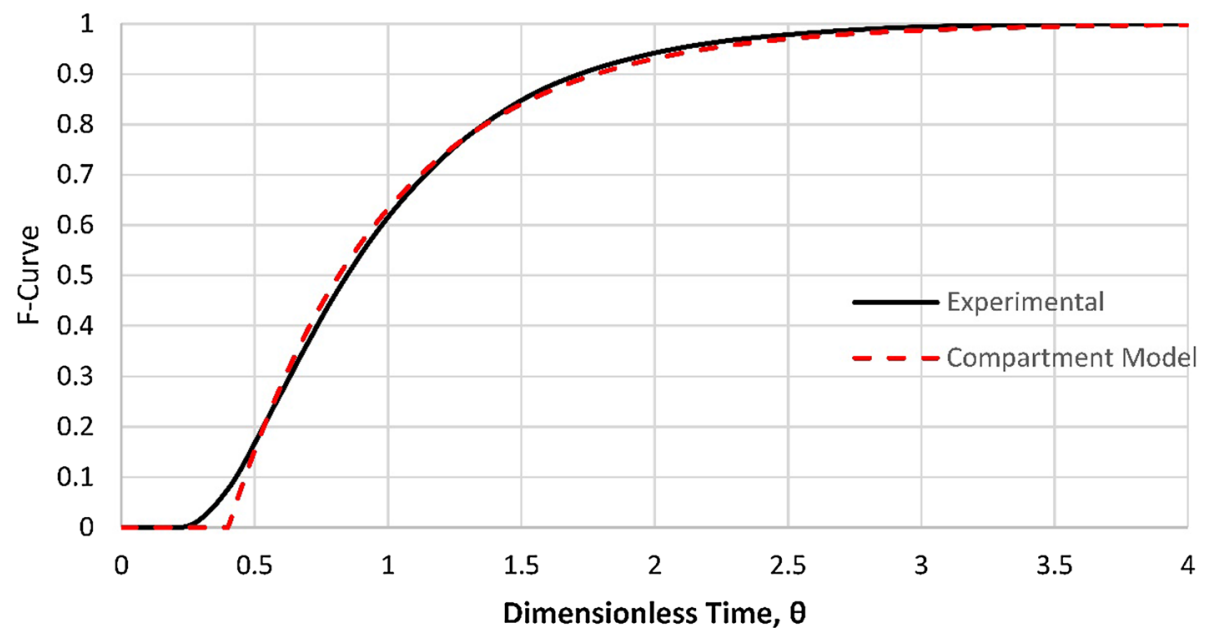

Fig. 1-Comparison of $F$-curves obtained experimentally and predicted by the compartment model.

hand, if the "New Method" were used, one would get $V_{\mathrm{p}} / V \cong 0.276, V_{\mathrm{m}} / V \cong 0.697$, and $V_{\mathrm{d}} / V \cong 0.027$.

An alternative approach is also available, which is particularly useful for studying asymmetric tundishes. ${ }^{[9]}$ Since the "active" volume associated with each strand is unknown, the average residence time associated with each strand is also unknown. So, it is interesting to evaluate the average residence time for each strand, $\bar{t}(\mathrm{~s})$. It can be calculated from both the $E$-curve and $F$-curve of each strand: ${ }^{[10]}$

$$
\begin{gathered}
\bar{t}=\int_{0}^{\infty} t \cdot E(t) d t \\
\bar{t}=\int_{0}^{\infty} 1-F(t) d t,
\end{gathered}
$$

where $E$ is the $E$-curve $\left(\mathrm{s}^{-1}\right)$ and $F$ is the $F$-curve.

The adequacy of this last approach is supported by some literature results ${ }^{[11,12]}$ of particle flotation in a water physical model.

The authors acknowledge the financial support of CAPES/PROEX to the graduate program. The doc- toral scholarship, No. 1487157, from CAPES to B. Martins Braga is also acknowledged.

\section{REFERENCES}

1. D. Li, H. Cui, Y. Liu, E. Tian, and J. Du: Metall. Mater. Trans. B, 2016, vol. 47B, pp. 1237-42.

2. Y. Sahai and T. Emi: ISIJ Int., 1996, vol. 36, pp. 667-72.

3. O. Levenspiel: Chemical Reaction Engineering, 3rd ed., Wiley, New York, 1998, pp. 283-86.

4. S.P. Ferro, R.J. Principe, and M.B. Goldschmit: Metall. Mater. Trans. B, 2001, vol. 32B, pp. 1185-93.

5. R. Sánchez-Ramírez, M. Díaz-Cruz, and R. Macías-Salinas: Can. Metall. Q., 2013, vol. 52, pp. 166-75.

6. D.C. Montgomery, E.A. Peck, and G.G. Vining: Introduction to Linear Regression Analysis, 3rd ed., Wiley, New York, 2001, pp. 414-20.

7. A.F.G. Mendonça: Masters Dissertation (in Portuguese), UFMG, Brazil, https://www.ppgem.eng.ufmg.br/defesas/951M.PDF, 2016. Accessed 02 Apr 2018.

8. Define and solve a problem by using Solver (Office Support), https://support.office.com/en-us/article/Define-and-solve-aproblem-by-using-Solver-5d1a388f-079d-43ac-a 7eb-f63e45925040, 2015. Accessed 02 Apr 2018.

9. H. Lei: Metall. Mater. Trans. B, 2015, vol. 46B, pp. 2408-13.

10. O. Levenspiel: Tracer Technology-Modeling the Flow of Fluids, 1st ed., Springer, New York, 2012, pp. 5-10.

11. H. Kim: PhD thesis, McGill University, Canada, http://digitool. library.mcgill.ca/thesisfile19523.pdf, 2003. Accessed 02 Apr 2018.

12. S.K. Ray: Masters Thesis, McGill University, Canada, http:// digitool.library.mcgill.ca/thesisfile99013.pdf，2006. Accessed 02 Apr 2018. 